\title{
FLOW-THROUGH ELECTROCHEMISTRY IN THE ANALYSIS OF WINE
}

\author{
ERNEST BEINROHR ${ }^{1,2}$, STANISLAVA HLUBIKOVA ${ }^{2}$, JARKA \\ LASTINCOVA $^{3}$
}

${ }^{1}$ Department of Chemistry, University of SS. Cyril and Methodius, J. Herdu 2, Trnava, SK-917 01, Slovak Republic (ernest.beinrohr@stuba.sk)

${ }^{2}$ Institute of Analytical Chenistry, Slovak Technical University, Radlinskeho 9, 81237

Bratislava, Slovak Republic (stanislava.hlubikova@stuba.sk)

${ }^{3}$ Central Controlling and Testing Institute in Agriculture UKSUP, Matuskova 21, 83316 Bratislava, Slovak Republic (lastincovaj@uksup.sk)

\begin{abstract}
Flow through coulometry is used for analysis of wine samples for the determination of some heavy metals, sulphites, acidity and ethanol content. Low concentrations of heavy metals and sulphite contents are determined by making use of stripping chronopotentiometry. For the measurement of acid and ethanol content thin-layer coulometric titration is used.
\end{abstract}

Key words: wine analysis, flow-through coulometry, heavy metals, sulphite, acids, ethanol

\section{Introduction}

Wine is a traditional beverage consumed all over the world. Its quality depends not only on the sensoric characteristics but also on the presence, or better absence of undesirable, mostly allergic or even toxic substances, such as heavy metals, high sulphite contents. Acid and ethanol contents significantly influence the taste and longterm stability of wines.

Electrochemical methods provide a useful tool for simple, fast and economical determination of numerous species in wine samples. Incorporating the measuring cell into a flow system it is possible to provide the analysis on full automated manner, controlled by a PC or microprocessor. Electrochemical flow-through cells specially designed for automatic and virtually maintenance-free operation facilitate the measurement of various species in wine samples: heavy metals ( $\mathrm{Cd}, \mathrm{Pb}, \mathrm{Hg}$ ), semimetals (As, Se), anions (sulphite, chloride), organics (ethanol, ascorbic acid, tartric acid).

The measurement of heavy metals is based on the deposition/stripping procedure, where the metal ions are electrochemically deposited on the electrode surface and then are stripped by constant current whereas the duration of the stripping is measured. This mode enables the measurement of low metal concentrations, down to the $\mu \mathrm{g} / \mathrm{l}$ contents. Sulphite (as free $\mathrm{SO}_{2}$ or total sulphite) can be measured in a similar way, just making use of a special gold coated electrode adsorbing $\mathrm{SO}_{2}$ molecules. The interfering effect of other species, especially those of chloride ions is eliminated by making use of an on-line silicone separator. The procedure was successfully applied for beer samples (DVORAK et al., 2006). The acid content is determined by direct reduction of $\mathrm{H}^{+}$ions 
to hydrogen in an encapsulated gold or platinum electrode, whereas ethanol is measured through its electrochemical oxidation to acetaldehyde on a platinum electrode coated with a catalytic surface.

\section{Experimental}

Flow-through electrochemical measurements were carried out by an electrochemical analyser EcaFlow 150 (Istran, s.r.o., Bratislava, Slovakia), equipped with two solenoid valves, a peristaltic pump, $1 \mathrm{~mm}$ inned diameter PTFE tubing and a microprocessor controlled potentiostat/galvanostat. The block diagram of the system is depicted in Fig. 1.

Electrolyte

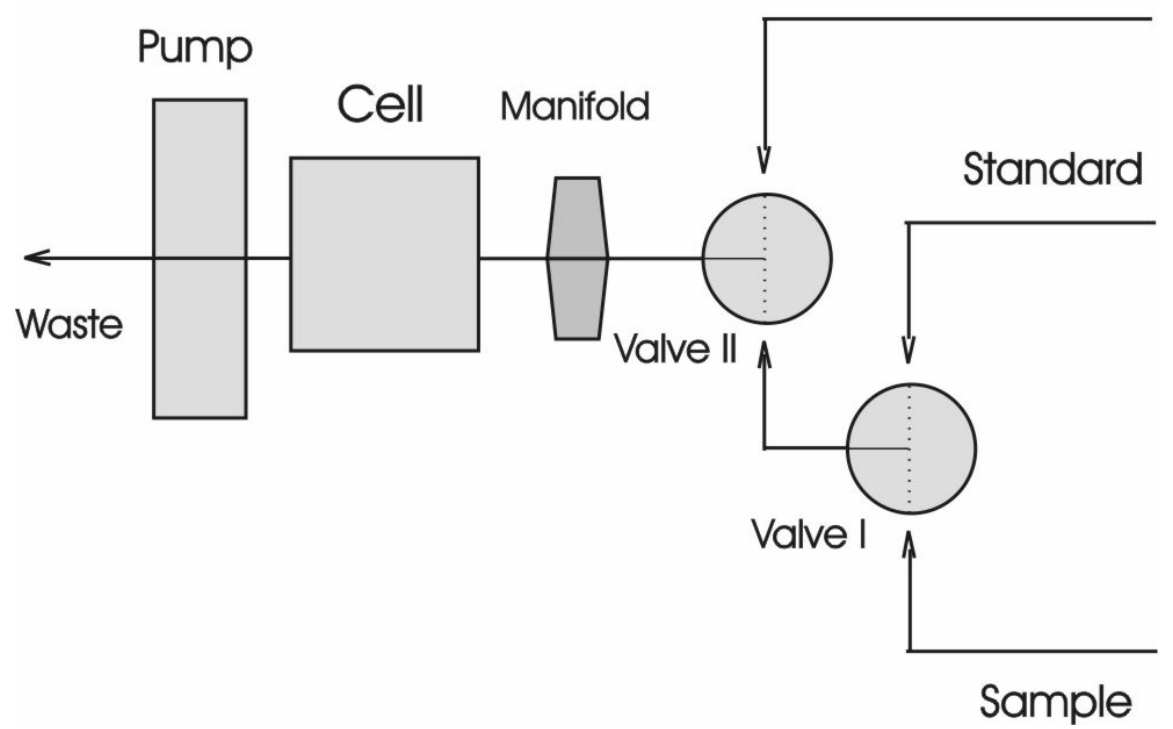

Fig. 1. Block diagram of the flow-through analyser EcaFlow (BEINROHR et al., 1999). The pump can be positioned downstream or upstream to the cell. The manifold is an option and may comprise a mixing chamber, in-line filter, etc. The flow rate is controlled by the tube diameter of the peristaltic pump and by its revolution rate.

The signals were recorded and evaluated by the memory-mapping technique (THOMSEN et al., 1994). Compact flow-through electrochemical cell of type 353c and 104 with Pt auxiliary and Ag/AgCl reference electrodes were used (Istran, s.r.o., Bratislava, Slovakia). The working electrodes used were of the type of E-56L or E104L (Zn, Cd, Pb, Cu), E-T/AX (sulphite), E-T/Pt (acids, ethanol) (all of Istran, s.r.o., Bratislava, Slovakia). The measurement consisted of two main steps: i) the background signal was measured first by means of the blank sample, ii) then, the sample or standard solution was measured. The background signal was then subtracted from this signal yielding a true background corrected net signal (MANOVA et al., 2007). 
Analytical-reagent grade chemical were used in all experiments. Deionised and degassed water was used for the preparation of all solutions.

\section{Results and discussion}

\subsection{Heavy metals}

Low concentration of heavy metals can be measured electrochemically after a preconcentration step ensuring the deposition of sufficient amount of analyte species on electrode. Then, the deposit can be dissolved ("stripped"), whereas the duration of the stripping is measured (stripping chronopotentiometry). Reasonable signal-tobackground ratios can be achieved even for very low concentrations. The measurement of $\mathrm{Zn}, \mathrm{Cd}, \mathrm{Pb}$ and $\mathrm{Cu}$ is usually done on mercury or mercury-coated electrodes, where corresponding amalgams are formed ( $\mathrm{M}$ denotes the corresponding metal):

Deposition: $\quad \mathrm{M}^{2+}+2 \mathrm{e}^{-}=\mathrm{M}(\mathrm{Hg})$

Stripping: $\quad \mathrm{M}(\mathrm{Hg})-2 \mathrm{e}^{-}=\mathrm{M}^{2+}$

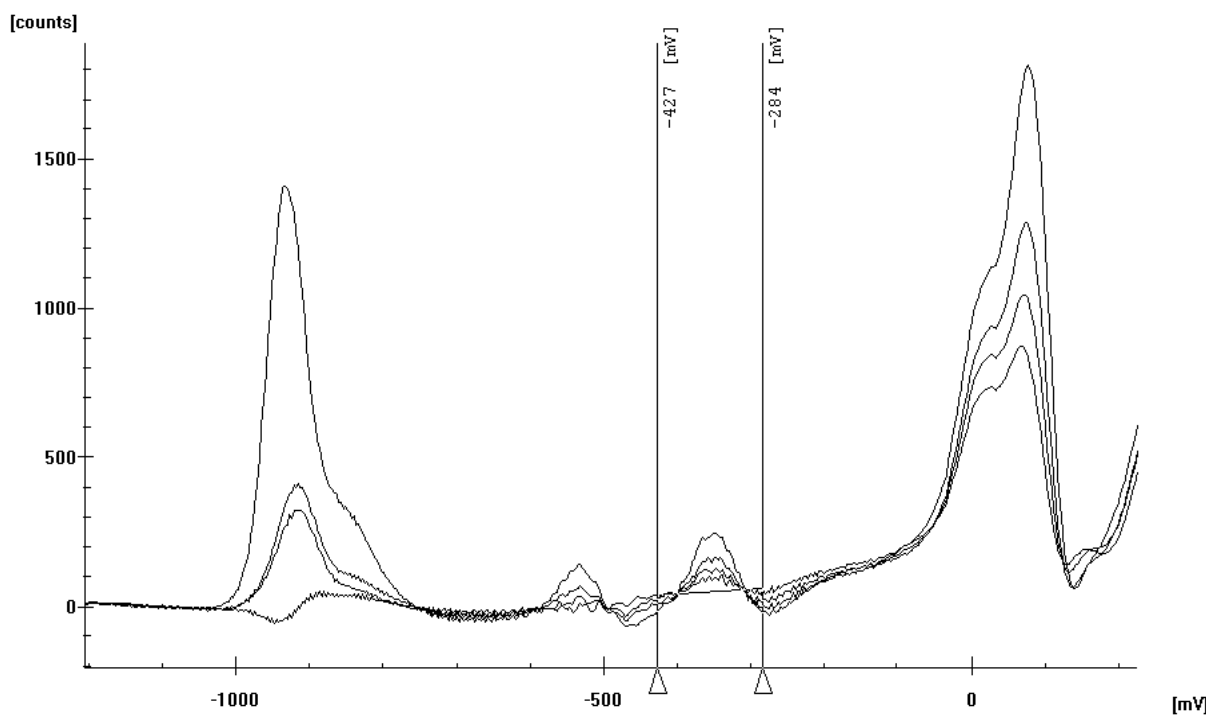

Fig. 2. Stripping chronopotentiograms of simultaneous measurement of $\mathrm{Zn}, \mathrm{Cd}, \mathrm{Pb}$, and $\mathrm{Cu}$ (signals from left to the right) in a red wine sample by the technique of standard additions. Sample diluted 10-times in 0.1 $\mathrm{mol} / \mathrm{l} \mathrm{HCl}$, carrier electrolyte $0.1 \mathrm{~mol} / / \mathrm{Na}_{2} \mathrm{SO}_{4}$ with acetate buffer ( $\mathrm{pH} 4.8$ ), electrode E-56L, deposition at $4 \mathrm{~mA}$, stripping with $0.2 \mathrm{~mA}$, sample volume $1 \mathrm{ml}$.

The former method makes use of hanging mercury electrode, the latter a thin layer of mercury, usually on carbon surface. Both approaches are less suitable for routine use, especially where mercury material or mercury plating solutions are not welcomed. A reasonable way is immobilise the mercury film into a compact electrode which is 
the used until fouling and then is returned to the producer for discharge. In this study a porous glassy carbon electrode with mercury and Nafion ${ }^{\circledR}$ coatings was used. The Nafion ${ }^{\circledR}$ film significantly enhances the stability of the mercury coating and eliminates interferences from many organic substances. Moreover, owing to its hydrophilic properties, bubbles are the easily removed from electrode bulk which enhances the signal reproducibility. However, the matrix of wine samples is complex and may interfere. To minimise this, the sample should be sufficiently diluted (LASTINCOVA et al., 2006). A typical recording of a red wine analysis is depicted in Fig. 2.

\subsection{Sulphites}

Sulphites are usually determined by the modified Monier-Williams method (AOAC, 2000) which is tedious and time consuming. Gold electrode materials may adsorb sulphur dioxide, which can be used for simple and fast sulphite determination in foods and beverages. Here, the sample is acidified to convert sulphites to sulphur dioxide, which is the collected on a suitable gold electrode. The adsorbed species are the galvanostatically oxidised, presumably to sulphate and the duration of this step is measured and evaluated. There are some interferences, the most serious one is associated with chloride anions. Adsorption may be a reason for this, which passivates the electrode surface. A simple way to minimise this is to utilise the easy diffusion of sulphur dioxide through a silicone membrane, whereas the interfering chloride ions remain in the original solution. A thin-wall silicone tube in a form of a submersible coil was used for this: The sample was acidified, the silicone coil was immersed into it and a trapping solution was pumped through the tube into the measuring cell. Obviously, the calibration should be done in the same fashion. Total sulphite content is determined after hydrolysing the sample on adding sodium hydroxide solution. Then, the released sulphite together with the free one is measured in the same way as free sulphite.

\subsection{Ethanol}

Ethanol can directly be oxidised electrochemically on platinum electrode, which is the principle of its potential use in fuel cells (IWASITA, 2002). The product of this oxidation is acetaldehyde up to carbon dioxide, depending on the conditions. The electrode surface should exhibit some catalytic properties towards ethanol oxidation. A simple way to achieve this is to coat the electrode with a thin layer of Nafion ${ }^{\circledR}$. A typical signal of ethanol measurement is depicted in Fig. 3.

Table 1. Analysis of wine samples for sulphite (BEINROHR et al., 2006)

\begin{tabular}{lll}
\hline Sample & ${\text { Free } \mathbf{S O}_{2}, \mathbf{~ m g} / \mathbf{l}}$ & Total SO $_{\mathbf{2}}, \mathbf{~ m g} / \mathbf{l}$ \\
\hline Müller Thurgau (Slovakia) & $45.1 \pm 3.1$ & $88.4 \pm 4.5$ \\
Rizling (Slovakia) & $54.3 \pm 4.3$ & $115 \pm 3.7$ \\
Cabernet Sauvignon (Slovakia) & $35.1 \pm 2.4$ & $79.6 \pm 5.7$ \\
Chiraz (California) & $56.2 \pm 4.2$ & $125 \pm 4.3$ \\
Vino di Tavola (Italy) & $31.5 \pm 2.6$ & $82.6 \pm 3.5$ \\
\hline
\end{tabular}




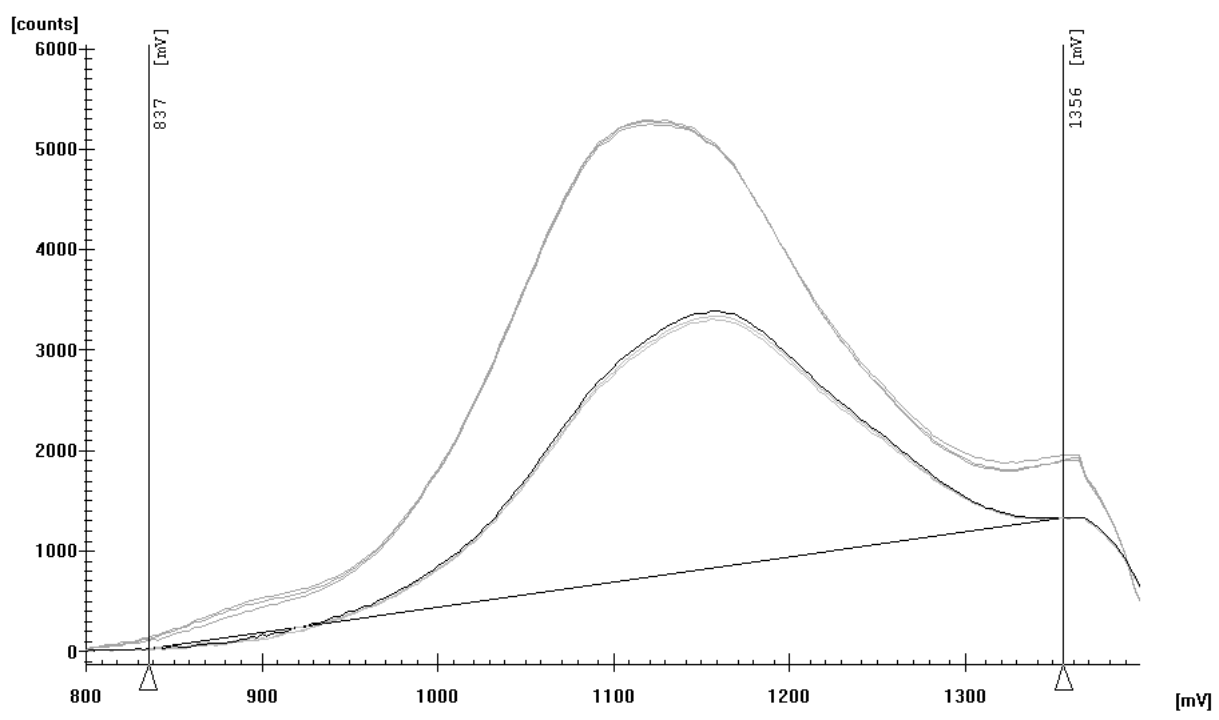

Fig. 3. Oxidation peak of ethanol in a diluted white wine sample (lower curves) and that for an ethanol standard in water $\left(0.0032 \%, \mathrm{~V} / \mathrm{V}\right.$, higher peak). Electrolyte $0.1 \mathrm{~mol} / \mathrm{l} \mathrm{Na} \mathrm{SO}_{4}$, electrode E-CA/Pt, oxidation current $5 \mu \mathrm{A}$.

\subsection{Acidity}

Acid-base titrations can easily be carried out electrochemically by making use of thin-layer cell arrangements. The neutralisation of hydroxonium ions is done by their direct electrochemical reduction to neutral hydrogen:

$2 \mathrm{H}_{3} \mathrm{O}^{+}+2 \mathrm{e}^{-}=\mathrm{H}_{2}+2 \mathrm{H}_{2} \mathrm{O}$

The sample should contain a neutral electrolyte not comprising species which are reduced at similar potentials as the hydroxonium ions. The potential of the reduction depends mainly on dissociation constant (-s) of the acid, the lower is the dissociation constant the more negative is the potential of the reduction and vice versa. At very low dissociation constants (below $10^{-7}$ ), the reduction peak of hydroxonium ions coalesce with the reduction of water. Dissolved oxygen is reduced as well and may contribute to the hydroxonium ion content if the concentration of the former is higher than that of the latter (about $10^{-4} \mathrm{~mol} / \mathrm{l}$ at room temperature). Anyway, it is possible to measure simultaneously strong and weak acids as it is known in volumetric titrations. The acidity of wines is expressed as tartaric acid content and is determined by volumetric titration either to a predefined $\mathrm{pH}$ value (e.g. $\mathrm{pH}$ 7) or to an indicator's colour change.

\section{Conclusions}

Flow-through coulometry has proved to be a suitable method for the determination of numerous species in wine samples. Its main advantage is simplicity, low costs and 
available instrumentation. However, only electrochemically active species can be measured and the elimination of possible interferences may be a problem, especially in wine samples with high sugar and carbon dioxide contents. The latter problem can be solved by proper sample preparation, e.g. by sample dilution and ultrasonic degassing. Anyway, the presented method may become a reasonable alternative or complement to spectroscopic and chromatographic methods in food and beverage analysis.

Acknowledgement: The financial support of the Slovak Ministry of Education (Applied Research Grant) is greatly appreciated.

\section{References}

AOAC Official Method 990.28.: Sulfites in Foods, Optimized Monier-Williams Method. AOAC Official Method of Analysis (2000) 47.3.43 p29.

BEINROHR, E CAKRT, M., DZUROV, J., JURICA, L., BROEKAERT, J. A. C.: Simultaneous calibrationless determination of zinc, cadmium, lead and copper by flow-through stripping chronopotentiometry. Electroanalysis, 11, 1999, 1137-1144.

BEINROHR, E., MANOVA, A., STRELEC, M., DZUROV, J.: Jednoduche a rychle stanovenie siricitanov vo vinach (Simple and fast determination of sulphites in wine). CHEMagazin, 16, 2006, 6-7.

DVORAK, J., DOSTALEK, P., STERBA, K., CEJKA, P., KELLNER, V., CULIK, J., BEINROHR, E.: Determination of total sulphur dioxide in beer samples by flowthrough chronopotentiometry. J. Inst. Brew., 112, 2006, 308-313.

IWASITA, T.: The electrocatalysis of ethanol oxidation. Proceedings of the $3^{\text {rd }}$ LAMNET Workshop, Brasil, 2-4 December, 2002, 76-83.

LASTINCOVA, J., CAVOJCOVA, I., POSPISILOVA L., BEINROHR, E.: Proceedings of the XXXth OIV World Congress, Budapest, Hungary, 10-16 June, 2007.

MANOVA, A., HUMENIKOVA, S., STRELEC, M., BEINROHR, E.: Determination of Chromium(VI) and Total Chromium in Water by In-Electrode Coulometric Titration in a Porous Glassy Carbon Electrode. Microchim. Acta, 159, 2007, 41-47.

THOMSEN, K. N., SKOV, H. J., DAM, M.: A flexible instrument for voltammetry, amperometry and stripping potentiometry. Anal. Chim. Acta, 293, 1994, 1-8. 